\title{
Ease of use of the ELLIPTA dry powder inhaler: data from three randomised controlled trials in patients with asthma
}

npj Primary Care Respiratory Medicine (2014) 24, 14019; doi:10.1038/npjpcrm.2014.19; published online 26 June 2014

Maintenance therapies for asthma are typically delivered via handheld inhalers. Poor adherence to inhaled medications and incorrect inhaler technique are known to adversely affect outcomes in asthma, contributing to the continuing failure for many patients to achieve control despite the availability of effective therapies. ${ }^{1}$

The ELLIPTA dry powder inhaler (DPI) is a handheld inhaler with single-step activation, featuring a cover that is opened by the patient to uncover the mouthpiece and activate a dose ${ }^{2}$ (ELLIPTA is a trademark of the GlaxoSmithKline group of companies). The actuated dose is subsequently inhaled from the mouthpiece. ${ }^{2}$ The ELLIPTA DPI is used to deliver fluticasone furoate (FF), a new inhaled corticosteroid licensed in Europe in combination with vilanterol, a new long-acting $\beta_{2}$-agonist, for asthma and chronic obstructive pulmonary disease and in development as a monotherapy for asthma. The aim of this analysis was to investigate patient perception of the ease of use, and investigator-reported competence in use, of the ELLIPTA DPI.

We describe a sub-analysis of the ease of use and inhaler competence data in patients with asthma from three randomised, multicentre clinical trials of FF/vilanterol combination therapy (HZA106827 (100/25 $\mu \mathrm{g})$ and/or FF monotherapy (FFA114496 $(100,200 \mu \mathrm{g})$; FFA115283 $(50 \mu \mathrm{g})$; HZA106827 $(100 \mu \mathrm{g})$ ), in which the ELLIPTA DPI was used to deliver study medication (including placebo where applicable). Preliminary results have been published in abstract form. ${ }^{2}$ The primary clinical trial data are reported separately. ${ }^{3-5}$

Patients completed a questionnaire at week 4 of each trial, rating the ease of use of the inhaler and how easy it was to tell how many doses of medication were left in the inhaler. For both questions, patients selected their response from the following ordinal scale: very easy, easy, neutral, difficult, and very difficult. Investigators assessed, by observation, patients' competence in using the ELLIPTA DPI following one demonstration of correct usage at randomisation, at week 2 and at week 4. Data were analysed and interpreted descriptively; no statistical inference was planned.

A total of 1,050 asthma patients (Supplementary Appendix) participated in the trials. Of these, $94 \%$ completed the questionnaire. Patient-reported ease of use and investigator-reported inhaler use assessment findings for each of the three clinical trials, together with pooled results, are presented in Table 1. The findings of both assessments were similar across the three trials (Supplementary Appendix).

Overall, $65 \%$ of questionnaire respondents reported that the inhaler was very easy to use, and $94 \%$ reported that it was easy or very easy to use. Only $1 \%$ of patients reported that the inhaler was difficult or very difficult to use. Similarly, $74 \%$ reported that they found it very easy to tell how many doses of medication were left in the inhaler using the in-built numerical dose counter, and $96 \%$ found it easy or very easy. Less than $1 \%$ of patients found it difficult or very difficult to tell how many doses were left in the inhaler.
At randomisation, investigators reported that $95 \%$ of patients used the inhaler correctly after the initial demonstration of correct usage at randomisation (week 0 ), and did not require additional instruction. A further $4 \%$ of patients were able to use the inhaler correctly at randomisation after one additional instruction. The most common error made at randomisation (before any additional instruction) was to open the cover incorrectly (20 (1.9\%) of all patients), followed by inhaling the dose incorrectly (15 (1.4\%)), unspecified reason $(12(1.1 \%))$, and closing the cover incorrectly (3 $(0.3 \%))$. At week 2 and week $4,>99 \%$ of patients used the inhaler correctly; four (0.4\%) patients made errors at week 2 and week 4, respectively (Supplementary Appendix).

In all three studies, the majority of participants found the inhaler to be easy to use, and were observed to use the inhaler correctly following a single demonstration. The design of the inhaler and appropriateness of the delivery mechanism to the patient may boost patient satisfaction with the medication regimen and competence in device use. ${ }^{6}$ Patient preference data obtained from a separate interview-based study ${ }^{7}$ are consistent with our findings, suggesting that patients with asthma and chronic obstructive pulmonary disease generally perceive the ELLIPTA DPI positively and find it easy to use.

A similar questionnaire has previously been used to assess comparative ease of use in asthma patients participating in randomised controlled trials, whose responses indicated that the DISKUS DPI is easier to use than DiskHaler. ${ }^{8,9}$ Similarly, our singledevice study was conducted against the background of randomised, controlled clinical trials in which all patients were given clear instruction in correct use of the inhaler at randomisation. Such thorough instruction is unlikely to be replicated in real-world clinical practice; ${ }_{i}^{10}$ this could therefore be considered a limitation in interpretation of this study.

The perceived and observed ease of use findings reported in this analysis suggest that the ELLIPTA DPI may have the potential to reduce inhaler-related handling errors and improve adherence; however, further studies are required to specifically assess these possibilities.

\section{ACKNOWLEDGEMENTS}

The authors are grateful to the statisticians who analysed the data from the individual clinical studies from which this letter reports findings from ease of use and inhaler competence sub-analyses: Richard Forth (for studies HZA106827 and FFA115283) and Anna Ellsworth (for study FFA114496) (GlaxoSmithKline). Editorial support in the form of development of the draft outline and manuscript first draft in consultation with the authors, editorial suggestions to draft versions of this paper, assembling tables and figures, collating author comments, copyediting, fact checking, referencing and graphic services was provided by lan Grieve at Gardiner-Caldwell Communications (Macclesfield, UK) and was funded by GlaxoSmithKline. lan provided editorial support but did not contribute to the design of the study or the analysis/interpretation of data, and his participation in the work is therefore insufficient to fulfil the ICMJE criteria for authorship.

\section{CONTRIBUTIONS}

$\mathrm{LJ}$ and CG conceived and designed the study. CG and HS analysed the data. All authors participated in the interpretation of the data, critically reviewed the paper and approved the final version of the paper for publication. HS is the study guarantor. 
Table 1. Summary of findings of ELLIPTA dry powder inhaler ease of use questionnaire and investigator assessment of inhaler technique for each study and when pooled together

\begin{tabular}{|c|c|c|c|c|}
\hline Ease of use questionnaire & $n=570$ & $n=213$ & $n=206$ & $N=989$ \\
\hline \multicolumn{5}{|c|}{ How did you rate the ease of use of the inhaler?, $n$ (\%) } \\
\hline Very easy & $362(64)$ & $146(69)$ & $132(64)$ & $640(65)$ \\
\hline Easy & $157(28)$ & $64(30)$ & $68(33)$ & $289(29)$ \\
\hline Very difficult & $1(<1)$ & 0 & 0 & $1(<1)$ \\
\hline \multicolumn{5}{|c|}{ How easily are you able to tell how many doses of medication are left in the inhaler?, $n$ (\%) } \\
\hline Very easy & $419(74)$ & $169(79)$ & $144(70)$ & $732(74)$ \\
\hline Easy & $126(22)$ & $42(20)$ & $51(25)$ & $219(22)$ \\
\hline Neutral & $22(4)$ & $2(<1)$ & $8(4)$ & $32(3)$ \\
\hline Difficult & $3(<1)$ & 0 & $1(<1)$ & $4(<1)$ \\
\hline \multicolumn{5}{|l|}{ Randomisation, ${ }^{a} n(\%)$} \\
\hline Patient used the inhaler correctly & $578(95)$ & $206(94)$ & $216(97)$ & $1,000(95)$ \\
\hline 1 Additional instruction required & $22(4)$ & $11(5)$ & $5(2)$ & $38(4)$ \\
\hline 2 Additional instructions required & $8(1)$ & $1(<1)$ & $1(<1)$ & $10(1)$ \\
\hline 3 Additional instructions required & $1(<1)$ & 0 & 0 & $1(<1)$ \\
\hline$>3$ Additional instructions required & 0 & 0 & 0 & 0 \\
\hline \multicolumn{5}{|l|}{ Week 2, n (\%) } \\
\hline$n$ & 593 & 215 & 216 & 1,024 \\
\hline Patient used the inhaler correctly & $593(100)$ & $211(98)$ & $216(100)$ & $1,020(>99)$ \\
\hline 1 Additional instruction required & 0 & $3(1)$ & 0 & $3(<1)$ \\
\hline 2 Additional instructions required & 0 & $1(<1)$ & 0 & $1(<1)$ \\
\hline 3 Additional instructions required & 0 & 0 & 0 & 0 \\
\hline$>3$ Additional instructions required & 0 & 0 & 0 & 0 \\
\hline \multicolumn{5}{|l|}{ Week $4, n(\%)$} \\
\hline
\end{tabular}

\section{COMPETING INTERESTS}

HS, LJ and CG are employees of and hold stock in GlaxoSmithKline. ERB has served as a consultant for AstraZeneca, Boehringer Ingelheim, Genentech, GlaxoSmithKline, Johnson and Johnson, Merck, Regeneron, Sanofi-Aventis and Forest, and has performed clinical trials for AstraZeneca, Boehringer Ingelheim, Cephalon, Forest, Genentech, GlaxoSmithKline, KalaBios, Medlmmune, Novartis and Sanofi-Aventis, which have been administered by his employer Wake Forest University School of Medicine.

\section{FUNDING}

This analysis (GSK study number HO-11-762) and the clinical trials during which the ease of use and inhaler competence data were collected were funded by GlaxoSmithKline (GSK study numbers (ClinicalTrials.gov number): HZA106827 (NCT01165138); FFA114496 (NCT01431950); FFA115283 (NCT01436071)). Employees of the sponsor had roles in the conception, design, and conduct of the study, as well as data collection and analysis. All authors participated in the development of the Article and had access to the data from the study. The decision to submit for publication was that of the authors' alone. GlaxoSmithKline did not place any restrictions on access to the data or on the statements made in the manuscript. The corresponding author had full access to all the data in the study, had final responsibility for the decision to submit for publication, and guarantees the data presented.

\author{
Henrik Svedsater ${ }^{1}$, Loretta Jacques ${ }^{2}$, Caroline Goldfrad $^{3}$ and \\ Eugene R Bleecker ${ }^{4}$ \\ ${ }^{1}$ Value Evidence and Outcomes, GlaxoSmithKline, \\ Stockley Park, Uxbridge, UK; \\ ${ }^{2}$ Respiratory Medicines Development Centre, \\ GlaxoSmithKline, Uxbridge, UK; \\ ${ }^{3}$ Quantitative Sciences Division, GlaxoSmithKline, \\ Uxbridge, UK and \\ ${ }^{4}$ Center for Genomics and Personalized Medicine, Wake Forest \\ School of Medicine, Winston-Salem, NC, USA \\ Correspondence: H Svedsater (henrik.x.svedsater@gsk.com)
}

\section{REFERENCES}

1 Roy A, Battle K, Lurslurchachai L, Halm EA, Wisnivesky JP. Inhaler device, administration technique, and adherence to inhaled corticosteroids in patients with asthma. Prim Care Respir J 2011; 20: 148-154.

2 Svedsater H, Jacques L, Goldfrad C, Bleecker ER, O'Byrne PM, Woodcock A. Ease of use of a two-strip dry powder inhaler (DPI) to deliver fluticasone furoate/vilanterol (FF/VI) and FF alone in asthma. Eur Respir J 2013; 42(Suppl 57): 128s-129s (abstract).

3 Bleecker ER, Lötvall J, O'Byrne PM, Woodcock A, Busse WW, Kerwin EM et al. Fluticasone furoate-vilanterol $100-25 \mathrm{mcg}$ compared with fluticasone furoate $100 \mathrm{mcg}$ in asthma: a randomized trial. J Allergy Clin Immunol In Pract (e-pub ahead of print 22 April 2014; doi:10.1016/j.jaip.2014.02.010). 
4 O'Byrne PM, Bleecker ER, Bateman ED, Busse WW, Woodcock A, Forth R et al. Once-daily fluticasone furoate alone or combined with vilanterol in persistent asthma. Eur Respir J 2013; 43: 773-782.

5 Woodcock A, Lötvall J, Busse WW, Bateman ED, Stone S, Ellsworth A et al. Efficacy and safety of fluticasone furoate $100 \mu \mathrm{g}$ and $200 \mu \mathrm{g}$ once daily in the treatment of moderate-severe asthma in adults and adolescents: a 24-week randomised study. BMC Pulm Med (in press).

6 Price D, Bosnic-Anticevich S, Briggs A, Chrystyn H, Rand C, Scheuch G et al. Inhaler competence in asthma: Common errors, barriers to use and recommended solutions. Respir Med 2013; 107: 37-46.

7 Woepse M, Dale P, Garrill K, Svedsater H, Walker R. Qualitative assessment of a new twin-strip dry powder inhaler (DPI) for asthma and COPD. BMC Pulm Med 2013; 13: 72.

8 Boulet LP, Cowie R, Johnston P, Krakovsky D, Mark S. Comparison of Diskus ${ }^{\mathrm{TM}}$ inhaler, a new multidose powder inhaler, with Diskhaler ${ }^{\mathrm{TM}}$ inhaler for the delivery of salmeterol to asthmatic patients. J Asthma 1995; 32: 429-436.
9 Pieters WR, Stallaert RALM, Prins J, Greefhorst AP, Bosman HG, van Uffelen R et al. A study on the clinical equivalence and patient preference of fluticasone propionate $250 \mu \mathrm{g}$ twice daily via the Diskus ${ }^{\mathrm{TM}} /$ AccuHaler $^{\mathrm{TM}}$ inhaler or the Diskhaler ${ }^{\mathrm{TM}}$ inhaler in adult asthmatic patients. J Asthma 1998; 35: 337-345.

10 Verver S, Poelman M, Bögels A, Chisholm SL, Dekker FW. Effects of instruction by practice assistants on inhaler technique and respiratory symptoms of patients. A controlled randomized videotaped intervention study. Fam Pract 1996; 13: 35-40.

(c) (i)

This work is licensed under a Creative Commons Attribution 4.0 International License. The images or other third party material in this article are included in the article's Creative Commons license, unless indicated otherwise in the credit line; if the material is not included under the Creative Commons license, users will need to obtain permission from the license holder to reproduce the material. To view a copy of this license, visit http://creativecommons.org/ licenses/by/4.0/

Supplemental Information accompanies the paper on the npj Primary Care Respiratory Medicine website (http://www.nature.com/npjpcrm) 